\title{
Autonomía y vulnerabilidad en la vejez: respuestas judiciales emblemáticas*
}

\section{María Isolina Dabove**}

Resumen. En este trabajo se debate acerca de la autonomía de la voluntad de las personas mayores en situación de dependencia a la luz del derecho de la vejez. Para ello, se estudia el sistema de la autonomía compuesto por la capacidad, la voluntad, la curatela y los sistemas de apoyo, asistencia y representación del código civil y comercial argentino, vigente desde agosto de 2015. Se analizan sus precedentes jurisprudenciales principales y su alcance valorativo. Además, se considera su articulación respecto de la reciente Convención Interamericana sobre la Protección de los Derechos Humanos de las Personas Mayores (CIDHPM) de la ozA, vigente desde el i I de enero de 20 I 7.

Palabras clave: derecho de las vejez, autonomía, capacidad, voluntad, vulnerabilidad, curatela.

Fecha de recepción: 27 de julio de 2017 . Fecha de aceptación: 8 de enero de 2018.

Para citar el artículo: Dabove, M. I., "Autonomía y vulnerabilidad en la vejez: respuestas judiciales emblemáticas", Revista de Derecho Privado, Universidad Externado de Colombia, n. ${ }^{\circ} 34$, enero-junio de 20I8, 53-85. DoI: https://doi.org/Io.I860I/oI 234366.n34.03

** Doctora en Derecho por la Universidad Carlos III de Madrid, España. Investigadora del Consejo de Investigaciones Científicas y Técnicas, Universidad de Buenos Aires. Abogada por la Universidad Nacional de Rosario. Directora del Centro de Investigaciones en Derecho de la Vejez de la Universidad Nacional de Rosario. Directora del Observatorio de Derechos Humanos de las Personas Mayores de la Universidad de Morón. Directora de la Unidad de Investigación en Derecho de la Vejez de la Facultad de Derecho y Ciencias Sociales de la Universidad Nacional de Córdoba. Integrante de la Delegación Oficial Argentina ante la onu y la oEA en el proceso de elaboración de la Convención Internacional y de la Convención Americana de Derechos Humanos de las Personas Mayores. Contacto: isolinadabove@gmail.com 


\section{Autonomy and Vulnerability of Elderly People: Emblematic Judicial Responses}

Aвstract. This paper discusses the private autonomy of older people when they are in situations of dependency according to the "Law of Old Age". For this, the author presents the autonomy system: the capacity, the will, the guardianship and the schemes of support, assistance and representation according to the Argentinean Civil and Commercial Code, in force since August 2015, its scope and the jurisprudence. In addition, it is considered the recent Inter-American Convention on the Protection of the Human Rights of Older Persons (CIDHPM) of the oAs, in force since January I I, 2017.

KeYwords: "Law of Old Age", autonomy, capacity, will, dependency situation, guardianship.

Sumario. Introducción. I. Cambios demográficos y derecho de la vejez. II. Autonomía, capacidad y voluntad en la vejez. A. Concepto y evolución de la capacidad en el derecho argentino. B. La voluntad: elemento imprescindible de los actos jurídicos. III. Restricciones a la capacidad de las personas mayores en situación de dependencia: la voluntad sitiada. Iv. Una nueva curatela: de la representación a la asistencia y apoyos razonables. v. Respuestas judiciales emblemáticas: pasado, presente y porvenir. A. Sobre la necesidad de distinción entre la vejez normal y la patológica. B. Importancia del contacto personal de los jueces con la persona en cuestión durante la tramitación del juicio. C. Gradualidad de las restricciones a la capacidad. D. Sobre curatela compartida. Reflexiones finales. Bibliografía.

\section{Introducción}

En el mundo jurídico la autonomía puede ser comprendida como aquel espacio individual en cuyo ámbito cada persona ejerce por sí misma el poder sobre su vida y su patrimonio, establece reglas, disposiciones o planes que solo a ella se refieren y le permiten proyectarse y desarrollarse, en igualdad de condiciones -aunque sin dañar- que los demás. Es el campo de independencia, dentro del cual cada sujeto despliega sus derechos y obligaciones fundamentales, en áreas claramente marcadas por la subjetividad, tales como la identidad, la vida y la salud, la integridad física y moral, el honor y la propia imagen, la intimidad, las libertades individuales -de circulación, de expresión, la libertad ideológica o de pensamiento, la libertad religiosa y la libertad sexual, entre otras-, la propiedad y su vinculación con los bienes y cosas, el domicilio, la vivienda y su hábitat (o medio ambiente), el trabajo, la ocupación y la recreación, su relación con los otros sujetos de derecho. 
La autonomía es también la esfera de libertad y de oportunidades vitales que le dan consistencia y realidad a nuestra condición de persona. Es el territorio individual que a cada uno le es posible sostener para sí, coexistiendo con el de los demás, en paridad de condición ${ }^{\mathrm{I}}$. Por ello, jurídicamente se articula con la capacidad y la voluntad de una persona. Con la capacidad, en cuanto atributo de la personalidad que el derecho reconoce junto al nombre, al domicilio y al estado. Con la voluntad, en cuanto elemento central de los hechos y actos jurídicos, a partir del cual la autonomía se pone en marcha y se determina el grado de responsabilidad de los sujetos intervinientes.

Desde el punto de vista filosófico de la cultura occidental, la de la autonomía ha sido siempre una problemática central. Entre otras razones, por ser la expresión más concreta de los debates en torno al ser humano, a la libertad, a la igualdad y a la fraternidad; a sus derechos y deberes fundamentales; tanto como por su lugar destacado en las teorías contractualistas, que justificaron la consolidación liberal del Estado moderno. Sea ello como fuere, como sabemos, estos debates alcanzan su punto culminante en la teoría kantiana de la autonomía como principio básico del sistema jurídico (imperativo categórico moral), cuyo presupuesto ineludible ha sido la asunción de un concepto abstracto, formal y pretendidamente universal de la persona ${ }^{2}$. Así, pues, inspirado en esta perspectiva filosófica, el derecho continental (europeo y latinoamericano, basado en el código civil francés de i 804) introduce la autonomía bajo la forma de un "principio general", aplicable principalmente al área de los contratos ${ }^{3}$.

Ahora bien, aun cuando este modelo abstracto de la persona y su autonomía resultó funcional a la realidad social y a los criterios de justicia del derecho continental -europeo y latinoamericano- del siglo xIx, a comienzos del xx una serie de acontecimientos habían comenzado ya a minarlo, para dar paso al escenario crítico y diverso en el cual estamos hoy insertos.

Un lugar destacado en este proceso lo ocupan, sin duda, la Revolución Industrial y los planteamientos referidos a la cuestión social de fines del siglo XIx. Pero también muchos otros, tales como los avances científicos y tecnológicos, los cambios demográficos concomitantes, traducidos en el aumento creciente y global de la expectativa de vida, el desarrollo del derecho laboral y de la seguridad social, el advenimiento del Estado de Bienestar y el constitucionalismo social del siglo xx, la configuración de las Naciones Unidas y el despliegue del proceso internacional de especificación de los derechos humanos de los grupos

I Dabove, M. I., "Autonomía y atención de las personas mayores en situación de dependencia en España: una cita entre generaciones", Oñati Socio-Legal Series, vol. I, n. ${ }^{\circ}$ 8, 3-2 7 .

2 Kant, I., La metafísica de las costumbres, A. Cortina y J. Conill Sancho (trad. y notas), Madrid, Tecnos, I989, 49-84; Kant, I., Crítica de la razón práctica, J. Rovira Armengol (trad.), 5. ${ }^{\text {a ed., }}$ Buenos Aires, Losada, I990, 2 I-32.

3 Nuevo código civil y comercial (CCCA), art. Iо, "Abuso del derecho". 
vulnerables claramente identificados a partir de 1950 , los procesos de integración regional, la constitucionalización de los derechos humanos y la instauración del actual modelo de Estado constitucional de derecho.

Estos fenómenos incidieron claramente en la crisis actual de la perspectiva clásica de la autonomía personal. Pero también fueron estímulos poderosos para la construcción de un nuevo modelo de autonomía personal, uno que permita comprenderla en su calidad de enclave y mandato de optimización de los derechos humanos, consensuados por la comunidad en su conjunto.

En el derecho privado argentino, el modelo posmoderno de autonomía personal quedó plasmado en el código civil y comercial (CCCA) con la asunción explícita de los derechos humanos en su texto. Así, el artículo I dispone: "Los casos que este Código rige deben ser resueltos según las leyes que resulten aplicables, conforme con la Constitución Nacional y los tratados de derechos humanos en los que la República sea parte. A tal efecto, se tendrá en cuenta la finalidad de la norma. Los usos, prácticas y costumbres son vinculantes cuando las leyes o los interesados se refieren a ellos o en situaciones no regladas legalmente, siempre que no sean contrarios a derecho".

Este trabajo aborda las teorías jurídicas en torno a la autonomía personal a partir del análisis de fallos significativos para el derecho privado argentino. Sin embargo, esta lectura se hará a la luz de una perspectiva particular: la problemática jurídica de la vejez; fenómeno inédito, creciente, altamente ambiguo y complejo. Para ello se estudiará el régimen jurídico de la capacidad y la voluntad, junto al de la curatela y los sistemas de apoyo, aplicables a las situaciones de dependencia que afecten a las personas mayores. La teoría trialista nos permitirá realizar esta indagación atendiendo a las perspectivas normativas, sociológicas y valorativas de este campo del mundo jurídico ${ }^{4}$.

Respecto de las fuentes normativas de derecho privado, junto al ccca se considerarán la Convención de los Derechos de las Personas con Discapacidad (n. ${ }^{\circ}$ 26378), la Ley de los Derechos de los Pacientes (n. ${ }^{\circ}$ 26529) y la Ley de Salud Mental (n. ${ }^{\circ}$ 26657). Mas también se abordarán los estándares de la nueva Convención Interamericana sobre la Protección de los Derechos Humanos de las Personas Mayores (CIDHPM). Este tratado regional fue aprobado por la Asamblea General de la oeA el I 5 de junio de 2015, entró en vigencia en el sistema interamericano desde el i I de enero de 2017 y cuenta con jerarquía superior a la ley (incluso al ccc) en Argentina por disposición constitucional. También haremos una breve referencia al actual desarrollo del proceso de elaboración de

4 Goldschmidt, W. Introducción filosófica al derecho: la teoría trialista del mundo jurídico y sus horizontes, 6. ${ }^{a}$ ed., Buenos Aires, Depalma, I987, I8-43; Ciuro Caldani, M. A., Estrategia jurídica, Rosario, unr Editora, 20I I, 9-23; Ciuro Caldani, M. A., Metodología jurídica y lecciones de historia de la filosofía del derecho, Rosario, Zeus, 2007, 39-45; íD., La conjetura del funcionamiento de las normas jurídicas: metodología jurídica, Rosario, Fundación para las Investigaciones Jurídicas, 2000, 7-28. 
la Convención Internacional de Derechos Humanos de las Personas Mayores de las Naciones Unidas, iniciado en diciembre de $20 \mathrm{Io}^{[5]}$. En el plano sociológico, se evaluará la evolución operada desde la jurisprudencia argentina, y en la esfera valorativa se observarán los criterios de legitimidad actualmente reconocidos como válidos. En las conclusiones se indicarán algunas recomendaciones que pueden ser de utilidad para el actual proceso de elaboración de la Convención Internacional de Derechos Humanos de las Personas Mayores, en curso desde el año 20 Io.

\section{Cambios demográficos y derecho de la vejez}

Como nunca antes había sucedido, el siglo xx nos legó la posibilidad de extender la duración de la vida, tal como lo acreditan los altos índices demográficos de esperanza de vida ${ }^{6}$. A tal punto que hoy, en el siglo xxI, el envejecimiento poblacional es considerado un fenómeno global y multigeneracional7. En anteriores investigaciones ${ }^{8}$ hemos destacado que el proceso de envejecimiento actual está caracterizado por un aumento generalizado y sostenido de la expectativa de vida en todo el mundo, así como por la feminización de la vejez, esto es, por la menor mortalidad de las mujeres mayores. Se trata de la ampliación cronológica de la vejez, como último estadio de la vida, con una duración promedio de 20 años por persona, con la existencia simultánea y en expansión de dos generaciones envejecidas, muchas veces no vinculadas por lazos de parentesco.

Ahora bien, respecto de la capacidad y la voluntad, la vejez supone una serie de modificaciones a nivel físico, psíquico y ocupacional de la persona, que se

5 Roqué, M., "El camino de la comunidad internacional”, en Dabove, M. I. (dir.), Derechos humanos de las personas mayores: acceso a la justicia y protección internacional, Buenos Aires, Astrea, 20 5 , $67-73$.

6 oms, Informe mundial sobre el envejecimiento y la salud, 2015, disponible en: http://www.who. int/ageing/publications/world-report-20 15/es/ [Consultado el ro de abril de 20 I 5]; NAcIonEs Unidas, cepal (2009); Instituto Nacional de Estadística y Censos [Argentina], Encuesta nacional sobre calidad de vida de adultos mayores $20 \mathrm{I}_{2}$ ENCaViAM: principales resultados, 20I3, disponible en: http://www.indec.gov.ar/ftp/cuadros/sociedad/encaviam.pdf [Consultado el I 5 de septiembre de 20I4].

7 Daвove, M. I., "Derecho y multigeneracionismo: o los nuevos desafíos de la responsabilidad jurídica familiar en la vejez", Revista de Derecho de Familia, n. ${ }^{\circ}$ 40, julio/agosto, 2008, 39-54; íD., "Elder Law: A need that emerges in the course of life", Ageing International, September 20 3 , DOI: IO.IOO7/si 2 I26-OI3-9I93-4; Lesson, G., "Demography, politics and policy in Europe", en Ludow, P. (ed.), Setting EU Priorities 2009, The European Strategy Forum, Ponte de Lima, Portugal, 2009, IO2-I 24; ÍD., "Future ageing in Southeast Asia: Demographic trends, human capital and health status", en Nurvidya, E. y Ananta, A. (eds.), Older Persons in Southeast Asia, Institute of Southeast Asian Studies (ISEAS), Singapore, 2009, 47-67; íD., "Prepared or not, Latin America faces the challenge of aging, current history", fournal of Contemporary World Affairs, vol. I IO, n. ${ }^{\circ} 733$, 20 I I, $75^{-80}$.

8 Daвоve (dir.), Derechos humanos de las personas mayores: acceso a la justicia y protección internacional, cit., I I-I4. 
traducen en un cambio en la autovaloración, en la relación con la sociedad y, principalmente, en la inserción familiar 9 . Esta situación suele dar lugar a una crisis de identidad, denominada "gerontolescencia", con consecuencias no siempre positivas para la persona mayor aun cuando sea transitoria en el tiempo ${ }^{\mathrm{IO}}$. Así, no obstante que la persona (o un grupo poblacional) viva una vejez normal o "no patológica", en este estadio no siempre es posible ejercer con plenitud todas las potencialidades que en ella están implícitas. No siempre le es factible a la persona el acceso a un conjunto de condiciones que le aseguren algún tipo de equilibrio bio-psico-social, apto para el desarrollo de sus planes de vida. No es habitual, en definitiva, que pueda disfrutar de su autonomía personal, del marco de libertad básico para el ejercicio de sus derechos y obligaciones y para su desarrollo vital, en igualdad de condiciones con todas las demás. Es pues este escenario ambivalente el que coloca a las personas de edad avanzada en una posición jurídica desventajosa, siempre "en riesgo" de ser lesionadas física o moralmente; de ser privadas, en suma, del espacio necesario para el ejercicio de la autonomía de la voluntad ${ }^{\mathrm{I}}$.

En este escenario se fue configurando una nueva especialidad de carácter transversal, denominada derecho de la vejez (o derecho de la ancianidad), destinada al estudio de la condición jurídica de las personas mayores, de 60 años en adelante $^{\mathrm{I} 2}$. Su objeto consiste en identificar y comprender la situación jurídica de las personas mayores en el derecho interno, regional e internacional. Pero, además, estudia las herramientas jurídicas de intervención que pueden y deben ser utilizadas respecto de las situaciones de aminoración, vulnerabilidad, discriminación, inestabilidad y/o abuso en general, que puedan padecer estos sujetos por el hecho de ser "viejos".

Como ya lo hemos señalado en otras oportunidades, esta rama está fundada en los derechos humanos y cuenta con una fuente normativa sumamente importante para nuestra región: la ciDHpm. Este tratado fue aprobado por la Asamblea General de la Organización de Estados Americanos (OEA), el I 5 de junio de 20 I 5 , entró en vigencia el I I de enero de 2017 y ya cuenta con cinco ratificaciones (de Uruguay, Costa Rica, Bolivia, Chile y Argentina).

9 Ibíd., $75-85$.

io Kalache, A., "Entrevista”, La Nación, I4/Io/I3 , I8. Disponible en: http://www.lanacion.com. ar/I6290 I 7-alexandre-kalache-estamos-creando-una-nueva-etapa-de-la-vida-que-antes-noexistia-yo-lo-llamo-gerontolescencia [Consultado el i 5 de agosto de 2015].

i I Herrera Ponce, M. S. et al., "Estigmas en torno a las demencias y las implicancias en el cuidado de patologías demenciales de las personas mayores", en Kornfeld Matte, R.; Fernández Lorca, M. B. y Belloni Symon, C. L. (eds.), Personas mayores y demencias: realidad y desafíos, Santiago de Chile, Pontificia Universidad Católica de Chile, 2015, 39-64.

I 2 Dabove (dir.), Derechos humanos de las personas mayores, cit., 9-44; Dabove, Elder Law, cit., I38I48; íD. y Prunotto Laborde, A. (dirs.), Derecho de la ancianidad: perspectiva interdisciplinaria, Rosario, Juris, 2006, 9-58; íD., Los derechos de los ancianos, Buenos Aires, Ciudad Argentina, 2002, 4I5-46I. 
No obstante, cabe recordar que el derecho de la vejez tiene otros precedentes relevantes debidos a la acción de las Naciones Unidas. Entre ellos cabe destacar el Primer Plan de Acción de Viena sobre el Envejecimiento de I982, el Segundo Plan de Acción de Madrid de 2002, los Cinco Principios de las Naciones Unidas a favor de las personas de edad de r99i y la constitución de los "Grupos de Trabajo de Composición Abierta" desde diciembre de 20 Io, en cuyo marco actualmente se está trabajando en la elaboración de la convención internacional en esta materia. Por último, es preciso resaltar la creación del cargo de "experta independiente", ejercido por Rosa Kornfeld-Matte, quien se encarga de auditar el estado de los derechos de las personas mayores ${ }^{\mathrm{I}}{ }^{3}$.

La autonomía y la atención de las personas mayores en situación de dependencia constituyen problemáticas que atraviesan todos los ejes del derecho de la vejez: la condición jurídica de la persona mayor y sus atributos; los derechos humanos de autonomía, los de participación, los referidos a los cuidados, y el acceso a la justicia ${ }^{\mathrm{I}}$. Incluso, la сіDHPм así lo reconoce en su artículo 7 cuando establece: "Los Estados Parte en la presente Convención reconocen el derecho de la persona mayor a tomar decisiones, a la definición de su plan de vida, a desarrollar una vida autónoma e independiente, conforme a sus tradiciones y creencias, en igualdad de condiciones, y a disponer de mecanismos para poder ejercer sus derechos". En este estudio se analizará la problemática de la vulnerabilidad en relación con la capacidad jurídica y la voluntad; junto a la cuestión de la autodeterminación de las personas mayores y al ejercicio de sus derechos humanos.

\section{Autonomía, capacidad y voluntad en la vejez}

En el derecho argentino, la capacidad y la voluntad son elementos constitutivos de la autonomía y de la posición que cada persona puede adoptar dentro del sistema jurídico; es decir, de su condición de sujeto de derechos y obligaciones ${ }^{15}$. Por su intermedio, cada persona despliega su vida y produce actos jurídicos ${ }^{16}$. En suma, genera "hechos humanos voluntarios, lícitos, que tienen por fin inmediato la adquisición, modificación o extinción de relaciones o situaciones jurídicas” (art. 259 CCCA; art. 944 CCA).

ÍD. (dir.), Derechos bumanos de las personas mayores, cit.

I4 Ibíd.; ÍD., Elder Law, cit., I 38 -I 48; íd. y PrunotTo, ob. cit., 9-58; íD., Los derechos de los ancianos, cit., 4I 5-46I.

i5 Rajmil, A. B. y Llorens, L. R., "Apuntes acerca del régimen de capacidad de las personas humanas en el código civil y comercial de la República Argentina (Ley 26.994)", IUS. Revista del Instituto de Ciencias furídicas de Puebla, año Ix, n. ${ }^{\circ}$ 6, julio-diciembre 20 I 5, 89-I I 7; FERnández, S., "Ancianidad, autonomía y vulnerabilidad. Una mirada a la situación jurídica de los adultos mayores desde la reforma proyectada para el código civil argentino", Revista Derecho Privado, año I, n. ${ }^{\circ}$ 2, Buenos Aires, Infojus, 2012 , I39-163.

i6 Cifuentes, S., Negocio jurídico, 2. a ed., Buenos Aires, Astrea, 2004, 46-i i4; Zannoni, E. A., Ineficacia y nulidad de los actos jurídicos, Buenos Aires, Astrea, 20I 3, 24-45. 


\section{A. Concepto y evolución de la capacidad en el derecho argentino}

La capacidad es un atributo de la personalidad complejo, razón por la cual puede ser analizada en términos fácticos, normológicos y valorativos ${ }^{17}$. Desde el plano fáctico, la capacidad es la competencia o habilidad concreta y real de comprensión, decisión y acción que el derecho reconoce a todas las personas por igual, respecto de su esfera de libertad individual. Normativamente, la capacidad es también condición y fundamento de la autonomía individual y se define en el código civil y comercial argentino como la aptitud de toda persona (física o jurídica) para adquirir derechos y contraer obligaciones (art. 22 CCCA $)^{18}$. Reconocimiento que se justifica en términos valorativos, por ser cada persona un fin en sí19.

El derecho privado reconoce dos tipos de capacidad: a) la capacidad de derecho (art. 22 CCCA), es decir, la facultad de la persona para ser titular de derechos y obligaciones, y b) la capacidad de ejercicio, que se refiere a la aptitud para ejercer derechos y contraer obligaciones por sí mismo. En relación con las personas humanas ${ }^{20}$, a las que nos vamos a referir en este trabajo, la capacidad plena (de derecho y de hecho) se adquiere además de manera progresiva hasta alcanzar la mayoría de edad a los I 8 años $^{21}$. Una vez obtenida, no se pierde por el simple transcurso del tiempo. Solo causas graves, o situaciones que pongan en riesgo su vida o patrimonio, pueden dar lugar al establecimiento de restricciones a la capacidad, respecto de las cuales los jueces son los únicos habilitados para pronunciarse en su favor (art. 32 CCCA $)^{22}$. Así, pues, la capacidad continúa siendo "regla", incluso para la persona envejecida²3.

No obstante, en Argentina este régimen tuvo una importante evolución desde i 869 a nuestros días, pudiendo reconocerse en este proceso cinco hitos importantes. Dos de ellos tuvieron lugar antes de la última reforma de la Constitución de i994. Los otros, en cambio, se produjeron a partir de la adopción de la Convención Internacional de los Derechos de las Personas con Discapacidad (CDPD) de la Asamblea General de la onu (2006). Convención que, por su je-

I8 Art. 22 CCCA: "Capacidad de Derecho. Toda persona humana goza de la aptitud para ser titular de derechos y deberes jurídicos. La Ley puede privar o limitar esta capacidad respecto de hechos, simples actos, o actos jurídicos determinados".

i9 Rajmil y Llorens, ob. cit., 89- i 7; Toвías, J. W., Derecho de las personas, Buenos Aires, La Ley, 2009, 97-I 37 .

20 Art. 23 Ccca: "Toda persona humana puede ejercer por sí misma sus derechos, excepto las limitaciones expresamente previstas en este Código y en una sentencia judicial”.

2 I Art. 25 ccca: "Menor de Edad es la persona que no ha cumplido dieciocho años".

22 Art. 32 Ccca: "Personas con capacidad restringida y con incapacidad".

23 Daвove, I. M., "Voluntad, capacidad y derechos fundamentales en la vejez: el problema cotidiano de la autonomía jurídica frente al envejecimiento", en BAriffi, F. y Palacios, A., Capacidad jurídica, discapacidad y derechos humanos, Buenos Aires, ediar, 20 I 2, 36I-384; ÍD. y Prunotto, ob. cit., $70-85$. 
rarquía constitucional ${ }^{24}$, obliga al resto de las fuentes jurídicas (códigos, leyes nacionales, provinciales o locales, sentencias, etc.) a adecuar su contenido a lo que en ella se establece ${ }^{25}$.

El primer logro relevante en esta materia se produce en i 869, al sancionarse la Ley 340 que aprueba el código civil. Por esta vía se estableció el régimen jurídico general relativo a las personas (la capacidad y la incapacitación) y a los hechos y actos jurídicos respecto de los cuales se regula la voluntad -el discernimiento, la intención y la libertad-, entre otros. El código entró en vigencia para toda la República Argentina el i. ${ }^{\circ}$ de enero de i 87 г.

El segundo momento importante sucede en I968, con la sanción la Ley I 7.7 I I que reforma el viejo código e incorpora, además, la figura de la inhabilitación en el artículo ${ }_{5} 2$ bis.

El tercer cambio se generó en el año 2009, con la aprobación de la Ley 26.579, vigente desde el I. ${ }^{\circ}$ de enero de 20 iо. Allí se estableció la disminución de la edad para el acceso a la capacidad plena -o mayoría de edad-, de los 2 I a los i 8 años, adecuándose a la Convención Internacional de Derechos del Niño, constitucionalmente válida desde 1994 .

El cuarto paso se dio con la sanción de la Ley 26.378 de 2008 que aprueba la Convención sobre los Derechos de las Personas con Discapacidad (CDPD), y con la posterior entrada en vigor de la Ley de Salud Mental, n. ${ }^{\circ}$ 26.657, en el año 20Io/20 i . Con esta última se modificó el viejo código civil, especialmente en relación con el sistema de restricciones a la capacidad causadas por padecimientos en la salud mental (art. I 52 ter).

Entre los logros más recientes se destacan, de un lado, la sanción del ccca, vigente a partir del.$^{\circ}$ de agosto de 2015 . De otro, la aprobación y entrada en vigor de la сіDнрм ratificada ya por Argentina.

Ahora bien, el nuevo código incorpora principios relativos a la autonomía personal, a la capacidad, a la voluntad y a los instrumentos de apoyo, asistencia y salvaguarda, previstos en la $\mathrm{CDPD}^{26}$. De modo tal que así logra dar cumplimiento -al menos normativo- a la Primera Observación General de la onu (del Comité para la supervisión de la aplicación de los Estados parte de esta Convención),

24 Desde el 20r4, esta Convención tiene jerarquía constitucional (art. 75, inc. $22 \mathrm{CN}$ ).

25 Ver también onu, Asamblea General (I969/ı 980), Convención de Viena sobre el Derecho de los Tratados, art. 27.

26 United Nations, Committee on the Rights of Persons with Disabilities, Concluding Observations on the Initial Report of Argentina as Approved by the Committee at its Eighth Session ( $17-28$ September 20I 2), disponible en: http://www.refworld.org/docid/54993c374.html [Consultado el 20 de abril de 20I5]; íD., I I ${ }^{\text {th }}$ Session, 3I March-I I April 20I4. General comment n. ${ }^{\circ}$ I (2014) I, Article I 2: Equal recognition before the law, disponible en: http://daccess-dds-ny. un.org/doc/UnDoc/GEN/Gi4/o3 I/20/PDF/Gi403 I 20.pdf?OpenElement [Consultado el i I de julio de 2015]. 
que trata sobre el alcance y significado del artículo i 2 , los sistemas de apoyo y salvaguardias $^{27}$.

Por otro lado, conforme a la premisa establecida en el artículo $2 .^{\circ}$ ccca que reclama la interpretación sistemática de este código con las convenciones de derechos humanos, en el derecho argentino se introduce el modelo social de la discapacidad ${ }^{28}$. Modelo que considera que todas las personas con discapacidad -incluso aquellas que padecen deficiencia mental- tienen derecho a que el Estado les reconozca su capacidad jurídica, en igualdad de condiciones con todas las demás, acorde a los artículos I, 3, 5 y I 2 CDPD. Pero, además, en esta misma dirección, se rechaza categóricamente cualquier restricción a la capacidad jurídica que implique la sustitución de voluntad en forma genérica o expansiva ${ }^{29}$.

El cccA, pues, adopta los principios de la autonomía personal y la igualdad, como base para la articulación de la capacidad, la voluntad, los derechos y deberes referidos a las personas en situación de discapacidad. También extiende el alcance de los efectos de la Ley Nacional de Salud Mental, con algunos años de antelación $3^{30}$.

En el capítulo 2 del libro primero, el nuevo código establece una sección inicial destinada a los "Principios Generales" en materia de capacidad (arts. 2225). En su Sección Tercera, el artículo 3 I determina las reglas generales que se han de aplicar en todos los supuestos de restricción a la capacidad (capacidad restringida, incapacidad e inhabilitación). Concretamente, expresa:

La restricción al ejercicio de la capacidad jurídica se rige por las siguientes reglas generales: a. la capacidad general de ejercicio de la persona humana se presume, aun cuando se encuentre internada en un establecimiento asistencial; b. las limitaciones a la capacidad son de carácter excepcional y se imponen siempre en beneficio de la persona; c. la intervención estatal tiene siempre carácter interdisciplinario, tanto en el tratamiento como en el proceso judicial; d. la persona tiene derecho a recibir información a través de medios y tecnologías adecuadas

onu, Asamblea General, 2006, art. I2, y onu, Comité sobre los Derechos de las Personas con Discapacidad, 2014.

28 Preámbulo de la cDpd. onu, Asamblea General, 2006; Palacios, A., El modelo social de discapacidad: orígenes, caracterización y plasmación en la Convención Internacional sobre los Derechos de las Personas con Discapacidad, Madrid, Caja Madrid, 2008, I03-г67. En relación con la aplicación jurisprudencial del concepto del modelo social de la discapacidad, ver fallo de la Suprema Corte de Justica de México, Amparo en revisión I 59/20 I3, RACR, I6 de octubre de 20 I $3 .^{2}$

29 Abandona el fundamento proteccionista, que produce afectación de otros derechos tanto patrimoniales como personales. Al respecto ver Cuenca Gómez, P., "La configuración de los apoyos", Conferencia ALFA: Discriminación y grupos en situación de vulnerabilidad: género y discapacidad, Instituto de Derechos Humanos "Bartolomé de las Casas" (Universidad Carlos III de Madrid, Lima, Perú, 2 a 4 de septiembre, 20I4), I-20, disponible en http://idehpucp.pucp.edu.pe/ wp-content/uploads/20 I4/o9/La-configuraci\% $\mathrm{C}_{3} \% \mathrm{~B}_{3}$ n-de-los-apoyos-Patricia-Cuenca.pdf [Consultado el 30 de marzo de 2015].

30 Olmo, J. P., Salud mental y discapacidad, Buenos Aires, Dunken, 20 I4, 27-42. 
para su comprensión; e. la persona tiene derecho a participar en el proceso judicial con asistencia letrada, que debe ser proporcionada por el Estado si carece de medios; f. deben priorizarse las alternativas terapéuticas menos restrictivas de los derechos y libertades.

A su vez, a partir de estos principios, el código determina y condiciona las facultades judiciales para restringir la capacidad; determina las personas legitimadas para iniciar la acción; regula las medidas cautelares y el procedimiento posterior. Señala el alcance de la sentencia respectiva y la obligación de su inscripción en el Registro Civil y Capacidad de las Personas (de alcance nacional). Impone al juez interviniente, asimismo, el deber de mantener contacto personal con el presunto incapaz durante todo el proceso, conforme al principio general de maximizar el respeto de la autonomía personal.

\section{B. La voluntad: elemento imprescindible de los actos jurídicos}

Por otra parte, la voluntad constituye un dispositivo central para la caracterización de los hechos y actos jurídicos. Opera como una fuente de energía o de poder y permite a cada sujeto decidir, iniciar y desarrollar actividades por sí mismo. En relación con la capacidad, es también un instrumento jurídico complejo, ya que el código requiere para su configuración que la persona actuante exteriorice de alguna manera sus tres componentes internos: el discernimiento, la intención y la libertad (art. $262 \mathrm{CCA}^{3 \mathrm{I}}$ ). Para la doctrina civilista, el discernimiento es la facultad de razonamiento, o competencia personal, para conocer y distinguir lo bueno de lo malo, lo justo de lo injusto, lo conveniente de lo inconveniente. La intención, la tendencia o dirección de la voluntad, esclarecida por el discernimiento, que le permite a cada persona la ejecución de una acción. La libertad, por su parte, es entendida como la posibilidad de elección personal y la independencia del sujeto, para el ejercicio de sus derechos y obligaciones ${ }^{32}$.

Por otra parte, según el derecho privado, cada uno de estos componentes de la voluntad puede verse afectado a su vez por situaciones que lo vician, provocando con ello consecuencias negativas para el acto jurídico (su nulidad o anulación). Así, por ejemplo, el discernimiento puede estar viciado por el error (de hecho o de derecho), o bien por la demencia o falta de razón, de la persona actuante. La intención puede verse viciada por dolo, el deseo explícito de engañar o la lesión subjetiva; y la libertad, por la violencia o intimidación (arts. 265-278 cCCA) ${ }^{33}$.

3 I Art. 262: "Manifestación de la voluntad. Los actos pueden exteriorizarse oralmente, por escrito, por signos inequívocos o por la ejecución de un hecho material".

32 Cifuentes, Negocio jurídico, cit., 46- I I 4.

33 Zannoni, Ineficacia y nulidad de los actos jurídicos, cit. 
En la vejez es posible observar diferentes formas de vulnerabilidad a través de las cuales suele generarse cualquiera de los vicios de la voluntad anteriormente reseñados; o bien pueden transformarse en las situaciones discapacitantes contempladas en la Convención. En cualquier caso, la autonomía personal se compone del juego articulado de la capacidad y de la voluntad propia de cada sujeto. Pero se expresa, además, en toda posibilidad de concreción de hechos y actos jurídicos, a partir de los cuales se produce alguna adquisición, modificación, transferencia o extinción de derechos y obligaciones.

Las personas mayores, por ser capaces plenamente, no tienen por qué verse privadas de esta posibilidad, a menos que sea factible determinar judicialmente la afectación negativa y sostenida de alguno de los componentes de la voluntad. De los tres que la constituyen, el discernimiento y la libertad suelen ser los más implicados o comprometidos: el discernimiento, toda vez que el deterioro cognitivo pone en riesgo la vida o el patrimonio de la persona mayor, y la libertad, cuando se coarten indebida e ilegítimamente sus oportunidades de desarrollo individual, mediante la fuerza, el engaño o la intimidación (coacción psicológica).

Los prejuicios contra la vejez y los fenómenos de discriminación motivados en la edad ("viejismo") constituyen dos causales relevantes para que ello suceda con frecuencia. Sin embargo, urge de nuevo subrayar que en el derecho argentino solo la disminución importante o el quebranto del discernimiento dan lugar a fallos judiciales que restringen la capacidad de obrar de las personas de edad avanzada. Pero ello ocurre en precisas y determinadas circunstancias ${ }^{34}$. A continuación veremos estos temas más de cerca.

\section{Restricciones a la capacidad de las personas mayores en situación de dependencia: la voluntad sitiada}

El cccA reconoce tres tipos de situaciones limitantes de la capacidad de ejercicio: la capacidad restringida (art. 32), la inhabilitación (art. 48) y la incapacidad (o interdicción) 35 .

a. La capacidad restringida puede ser establecida por ley o por vía judicial, en los supuestos de deterioros cognitivos que afecten áreas importantes de la autonomía personal (su vida y/o su patrimonio) ${ }^{36}$. Desde el punto de vista ius-sociológico, estas limitaciones solo se pueden declarar cuando la persona padezca deficiencias significativas en su voluntad, sin que ellas interfieran completamente

Di Tullio Budassi, R., "La evolución legislativa y jurisprudencial en materia de salud mental referida a la vejez. Perspectiva en el derecho proyectado", Derecho de Familia. Revista Interdisciplinaria de Doctrina y Jurisprudencia, n. ${ }^{\circ}$ 6, septiembre, $2012,23-37$.

35 Art. 24 ccca: "Personas incapaces de ejercicio". Art. 32 in fine.

36 Olmo, J. P., Salud mental y discapacidad: adenda de actualización, Buenos Aires, Dunken, 20 I6, I 770; ín., Salud mental y discapacidad: análisis del código civil y comercial de la Nación, Buenos Aires, Dunken, 2017, I95-254. 
en su discernimiento. En este sentido, el artículo 32 establece: "El juez puede restringir la capacidad para determinados actos de una persona mayor de trece años que padece una adicción o una alteración mental permanente o prolongada, de suficiente gravedad, siempre que estime que del ejercicio de su plena capacidad puede resultar un daño a su persona o a sus bienes" 37 . En el plano valorativo, en este artículo se observa un avance respecto del anterior sistema, toda vez que incorpora nuevos y mejores instrumentos de solución. En particular, el nuevo CCCA señala que el juez debe designar el o los apoyos necesarios que prevé el artículo 43, especificando las funciones de acuerdo a las necesidades y circunstancias de la persona. Igualmente, estos apoyos deberán promover la autonomía y favorecer las decisiones que respondan a las preferencias de la persona protegida.

La Convención Interamericana, por su parte, refuerza esta misma perspectiva del ccca al establecer la temporalidad y especificidad de las sentencias que dispongan salvaguardias para el ejercicio de la capacidad de la persona mayor. También ordena que sean proporcionales y adaptadas a las circunstancias de la persona, que se apliquen en el plazo más corto posible y que estén sujetas a exámenes periódicos por parte del órgano o autoridad judicial (art. 30 CIDHPM).

b. La inhabilitación -introducida en I 968 en el derecho argentino sobre un campo más amplio-, ahora solo puede ser establecida respecto de los pródigos. El artículo 48 expresamente dice:

Pueden ser inhabilitados quienes por la prodigalidad en la gestión de sus bienes expongan a su cónyuge, conviviente o a sus hijos menores de edad o con discapacidad a la pérdida del patrimonio. A estos fines, se considera persona con discapacidad, a toda persona que padece una alteración funcional permanente o prolongada, física o mental, que en relación a su edad y medio social implica desventajas considerables para su integración familiar, social, educacional o laboral. La acción sólo corresponde al cónyuge, conviviente y a los ascendientes y descendientes.

En semejanza con las restricciones a la capacidad, la inhabilitación solo puede ser determinada por un juez; quien, en su sentencia, deberá individualizar y especificar las decisiones y actos jurídicos que requerirán asistencia y apoyo personal para lograr su validez (arts. 49 y 50 cCCA). De modo tal que, por su intermedio, se intentará el logro de una aspiración valorativa importante: la protección y empoderamiento de la vida independiente de la persona en cuestión y el amparo de todos aquellos que se vinculen con ella.

c. La incapacidad, por su parte, ha quedado convertida, ahora, en una medida judicial absolutamente excepcional, que puede ser declarada a una persona en

37 Un importante antecedente normativo de este supuesto es el artículo I 52 bis del código civil velezano. 
caso de que ella padezca un deterioro cognitivo de tal gravedad que le obstruya casi completamente la expresión de su voluntad (arts. 24 y 32 CCCA). Así, desde una perspectiva fáctica, el problema desencadenante de esta decisión es la falta de competencia total para actuar por sí mismo. En tanto que su consecuencia práctica será la pérdida de su capacidad de ejercicio y el desplazamiento de su voluntad por un curador, quien actuará en calidad de representante legal respecto de actos jurídicos determinados. Más aún, de acuerdo a la Convención Interamericana y a la Ley de Salud Mental, la sentencia deberá establecerse por un período de tiempo concreto (de tres años) y tendrá que especificar los actos para los cuales la participación directa del incapacitado resulta totalmente prohi$\mathrm{bida}^{3}{ }^{8}$. Desde un enfoque valorativo, la incapacidad es el último recurso que un juez puede utilizar para proteger la dignidad y la autonomía de quien no tiene margen para hacerse cargo de sí mismo, de ninguna manera (es el caso, p. ej., de alguien que se encuentra en estado vegetativo).

En la vejez, las restricciones a la capacidad de obrar están vinculados a las tres situaciones previstas en el cccA. Sin embargo, las más frecuentes e importantes son aquellas causadas por deterioros cognitivos, ya sean graves -Alzheimer avanzado, demencias seniles, etc.- o bien supuestos más leves de padecimiento mental o cuadros de alcoholismo y adicciones. La prodigalidad de las personas mayores también suele ir asociada a deterioros cognitivos (arts. 24, 32 y 48 $\left.\mathrm{CCCA}^{39}\right)$.

Por otra parte, también cabe subrayar que, con asiduidad, las personas (y los jueces) suelen confundir situaciones restrictivas de la capacidad con la "gerontolescencia" o crisis bio-psico-social de identidad, cuyos síntomas desencadenan conflictos afectivos, familiares y sociales, que impactan en la esfera patrimonial y en la autoestima ${ }^{\circ}$. En el inicio de la vejez es común que las personas mayores se vean literalmente impotentes para ejercer por sí mismas sus derechos por la situación de alta vulnerabilidad y "forzada discapacidad" 4 r a la que las someten los prejuicios culturales y las prácticas viejistas. También afectan su identidad las

$3^{8}$ Art. 152 ter CCA: "Las declaraciones judiciales de inhabilitación o incapacidad deberán fundarse en un examen de facultativos conformado por evaluaciones interdisciplinarias. No podrán extenderse por más de tres (3) años y deberán especificar las funciones y actos que se limitan, procurando que la afectación de la autonomía personal sea la menor posible" (artículo incorporado por el art. 42 de la Ley 26.657 , B.O. 3/12/2010).

Zannoni et al., Código civil y comercial. Concordado con el régimen derogado y referenciado con legislación vigente. Exégesis de los fundamentos de la Comisión redactora y las modificaciones del PEN, Buenos Aires, Astrea, 201 5, 39-45.

Iacub, R., Identidad y envejecimiento, Buenos Aires, Paidós, 201 I , I4-97.

4I Bach, M., "El derecho a la capacidad jurídica en la Convención de la onu sobre los Derechos de la Persona con Discapacidad: conceptos fundamentales y lineamientos para una reforma legislativa", en Palacios, A. et al., Capacidad jurídica, discapacidad y derechos humanos: una revisión desde la Convención Internacional sobre los Derechos de las Personas con Discapacidad, Buenos Aires, EDIAR, 2OI 2, 55-IO7. 
situaciones de abandono familiar, la reducción de los ingresos por causa de la jubilación o el cese de la relación laboral, la pérdida de afectos, rutinas y costumbres, la falta de vivienda o la desprotección en materia de salud, entre otros ${ }^{42}$.

Así, las demandas judiciales de revisión de la capacidad interpuestas abusivamente -con el propósito de usar coercitivamente estas instituciones a fin de lograr intervenir en la administración o en el manejo de los bienes- alteran la salud mental de las personas mayores. Son igualmente discriminatorias y "aminorantes" las decisiones judiciales que continúan considerando a la vejez (senectud) una enfermedad (senilidad); la falta de contacto directo de los jueces con la persona en cuestión, o bien la desconsideración judicial del criterio de gradualidad a la hora de establecer las restricciones para el caso43. Para contrarrestar estos escenarios negativos, en su artículo 35, el ccc ha previsto que los jueces tienen la obligación de realizar entrevistas personales al procesado por restricción a la capacidad, garantizar la accesibilidad e implementar los ajustes razonables que el caso requiera ${ }^{44}$.

\section{Una nueva curatela: de la representación a la asistencia $\mathrm{y}$ apoyos razonables}

Conforme a la tradición jurídica romanista, la curatela es un instituto tuitivo que tiene por finalidad el resguardo del bienestar, salud y/o patrimonio de una persona mayor de edad, cuyos deterioros cognitivos o volitivos le impiden hacerlo por sí misma ${ }^{45}$. Ahora bien, a raíz de la CDPD esta figura ha experimentado una serie de transformaciones que la hicieron más flexible y adecuada a las necesidades de la persona asistida. Comprende, así, tanto las tareas de representación como la de asistencia y otorgamiento de apoyos razonables ${ }^{4}$.

En Argentina, el artículo I 38 cCCA señala que la principal función del curador consiste en el cuidado de la persona y los bienes del sujeto restringido en su

42 Di Tullio Budassi, ob. cit.

43 Daвove, Voluntad, capacidad y derechos fundamentales en la vejez, cit.

44 Art. 35 ccca: "Entrevista personal. El juez debe garantizar la inmediatez con el interesado durante el proceso y entrevistarlo personalmente antes de dictar resolución alguna, asegurando la accesibilidad y los ajustes razonables del procedimiento de acuerdo a la situación de aquél. El Ministerio Público y, al menos, un letrado que preste asistencia al interesado, deben estar presentes en las audiencias". Garrido Cordobera et al., Código civil y comercial argentino. Comentado, anotado y concordado, t. I, Buenos Aires, Astrea, 20 I 5, 5 I-52; Sobre la evolución legislativa y jurisdiccional puede verse Olmo, Salud mental y discapacidad, cit., 26 I-280.

45 Fernández Mele y Goizueta, “Ancianidad e insania, comentario a fallo 'N. H. en nombre y representación de L. M. L. s/ curatela', Superior Tribunal de Justicia de Corrientes del 22/I I/20 I ", Revista de Derecho de Familia, vol. de jurisprudencia III/2013, I30-I44; DaYton, K., Comparative Perspectives on Adult Guardianship, Durham, Carolina Academic Press, 2004,

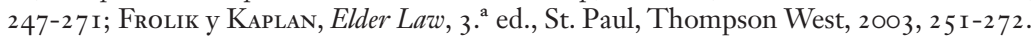

46 Olmo, Salud mental y discapacidad, cit., 2014, 293-303. 
capacidad, inhabilitado o incapaz, y en la tarea de recuperación de su salud, para lo cual debe destinar las rentas de los bienes de su asistido47. Pero, además, se reconocen varios modelos para su ejercicio. Dispone la posibilidad de establecer para el curado, o bien su representación, o bien una asistencia personal, apoyos o salvaguardas razonables. Estas asistencias pueden ser válidas solo durante la tramitación judicial (ad litem o provisorias), definitivas (a partir de la sentencia), puede tratarse de medidas de protección de la persona, de los bienes, o de la curatela completa (si estas últimas funciones recaen en una misma persona), conforme a los artículos 32 a 43 y $\mathrm{IOO}$ a $\mathrm{I}_{40} \mathrm{CCC}^{4}$.

No obstante, y tal como era en el viejo sistema, en la actualidad estas curatelas solo pueden establecerse por vía judicial, con la novedad de permitir también su ejercicio compartido, mediante designación de una o más personas para cumplir esta función (arts. I 38 ss. CCCA ${ }^{49}$ ). Así, el juez interviniente tiene a su cargo la responsabilidad de evaluar y decidir cuál tipo de asistencia y/o representación es la más adecuada y razonable para la persona en cuestión. Por ello, en esta instancia, la etapa probatoria de la salud mental es clave y fundamento de esta decisión.

La evolución de la capacidad en Argentina, favorable al reconocimiento máximo de la autonomía personal, incidió notablemente tanto en la regulación jurídica de la propia curatela como en la de las pruebas de los deterioros cognitivos.

Dentro del sistema previo a la Convención de Derechos de las Personas con Discapacidad (CDPD) y al CCC argentino, acreditados los supuestos para la restricción, el juez designaba un curador que tenía por misión asistir a la persona en aspectos específicos de su vida. A diferencia del curador de un incapaz absoluto, el curador del inhabilitado no tenía entonces funciones de representación sino de asistencia, pudiendo actuar solo de manera conjunta o complementaria a la actuación de la persona inhabilitada. El ámbito de actuación también era diferente pues, mientras el curador de una persona incapaz la representaba en todos los actos de la vida civil, el curador de la persona inhabilitada solo la asistía cuando realizaba actos relevantes con contenido patrimonial. Al mismo tiempo, el curador podía ser encargado de otras funciones, tales como garantizar que la persona reciba atención de salud, realizar actos patrimoniales de menor importancia, o bien efectuar actos de conservación del patrimonio, si la persona no estaba en condiciones de llevarlos a cabo en forma autónoma.

47 Art. I38 ccca: "Curatela. Normas aplicables. [...] La principal función del curador es la de cuidar a la persona y los bienes de la persona incapaz, y tratar de que recupere su salud. Las rentas de los bienes de la persona protegida deben ser destinadas preferentemente a ese fin". Véase Garrido Cordobera, L. et al., Código civil y comercial argentino. Comentado y concordado, t. I, Buenos Aires, Astrea, 20 I 5, I68-I 7 I.

48 Clusellas et al., Código civil y comercial. Comentado, anotado y concordado. Modelos de redacción sugeridos, t. I, Buenos Aires, Astrea, 201 5, $92-93$.

49 Art. i 38 ccca. Garrido Cordobera et al., ob. cit., i68-i 7 I. 
Con la CDPD, en cambio, todo el régimen de la curatela se flexibilizó a favor de su reconocimiento como instrumento de salvaguardia o apoyo. En esta dirección, muy esclarecedoras resultan tanto la doctrina de Costa Rica ${ }^{\circ}$ como la interpretación de la Convención de la Corte Suprema de Justicia de México sobre la necesidad de entender a la curatela como un sistema asistencia en la toma de decisiones ${ }^{5}$. Junto a lo cual, en materia de derecho de la vejez, cabe resaltar los postulados de la Declaración de Río de octubre de 2013 en relación con los cuidados de las personas mayores.

En suma, el derecho de fondo consagró garantías para que la persona en cuestión no se vea forzada a renunciar totalmente a su vida independiente y pueda ejercer el mayor grado de "autotutela o autoprotección" a su alcance (arts. I 38 -I4O CCCA $)^{52}$. Por esta razón, la clásica sustitución de voluntad del curador ha quedado reducida a medida de excepción (art. 32 cCCA $)^{53}$.

\section{Respuestas judiciales emblemáticas: pasado, presente y porvenir}

Tal como hemos advertido en anteriores investigaciones ${ }^{54}$, en la vejez es común observar diferentes formas de vulnerabilidad, entre las cuales se destacan los pedidos judiciales abusivos de restricción a la capacidad. Estas pretensiones acostumbran invocarse por causa de deterioros cognitivos, alcoholismo, adicciones, prodigalidad. Pero también en situaciones de "debilidades decisionales" basadas en prejuicios "viejistas" que asocian edad avanzada a proceso involutivo personal55. En esta ocasión, sin embargo, vamos a resaltar aquellas buenas prácticas generadas al amparo del antiguo código, que han abierto el camino judicial al nuevo paradigma de la autonomía de la voluntad del nuevo ccca. Para ello vamos a considerar los fallos en la materia establecidos con anterioridad a la CDPD y los posteriores a su incorporación al derecho interno argentino.

50 Álvarez Ramírez y Villarreal Arroyo, "Análisis de la curatela y la capacidad de actuar de las personas con discapacidad en Costa Rica, a la luz de la Convención sobre los Derechos de las Personas con Discapacidad”, tesis de licenciatura en Derecho, San José, Universidad de Costa Rica, 20Iо, I68-2 27. Disponible en: http://iij.ucr.ac.cr/sites/default/files/documentos/tıo- analisis_de_la_curatela_y_capacidad_de_actuar_de_personas_discapacitadas.pdf [Consultado el I 5 de abril de 20I4].

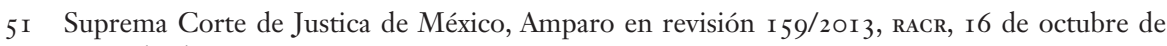
$20{ }_{3}, 63-64$.

52 Álvarez Ramírez y Villarreal Arroyo, ob. cit., i 68-22 7; Suprema Corte de Justica de México, Amparo en revisión I59/20I3, RACR, I6 de octubre de 2013, 65-66.

53 Art. 32 ccca. Ver Garrido Cordobera et al., ob. cit., 52-54.

54 Daвove, Voluntad, capacidad y derechos fundamentales en la vejez, cit., 36 I-384.

55 "La expresión del inc. $2 .^{\circ}$ plantea, además, la cuestión de la eventual inclusión en su ámbito de las denominadas 'debilidades decisionales', como la vejez o la ignorancia”: ТовíAs, "Capacidad. Inhabilitación judicial. La causal del inciso $2 .^{\circ}$ del artículo I 52 bis. Ámbito”, en Toвías, J. W., Colección de análisis jurisprudencial derecho civil: Parte general, Buenos Aires, La Ley, 2003. 
Del período anterior a la CDPD y al ccc argentino cabe destacar varios fallos con relación a cuatro temas de especial relevancia para el derecho de la vejez en este campo. El primero se refiere a la necesidad de distinción entre la vejez normal y la patológica; el segundo se vincula con la importancia del contacto personal de los jueces con la persona en cuestión durante la tramitación del juicio; el tercero considera la cuestión de la gradualidad de las restricciones a la capacidad, y el cuarto concierne a la curatela compartida. De la etapa posterior a la CDPD solo encontramos algunos fallos que amplían esta línea jurisprudencial.

\section{A. Sobre la necesidad de distinción entre la vejez normal y la patológica}

En este contexto cabe destacar la importancia del precedente "F. de G.B., A.C. s/ inhabilitación”, establecido por el fallo de la Cámara Nacional Civil de Buenos Aires, Sala D, de 22 de junio de I982. Estaba referido a la necesidad de distinguir entre la vejez normal y la senil o patológica para dar lugar a la inhabilitación solicitada $^{5}$. El decisorio, objeto de comentario de Josefa Méndez Costa ${ }^{57}$, concluyó que si bien la vejez trae aparejado un deterioro físico, el anciano puede conservar intactas y aun enriquecidas por la experiencia sus facultades mentales: "Ni la actitud básica de comprensión -el discernimiento- ni la adquirida razonabilidad de los juicios, ni la posibilidad de exteriorizar las resoluciones mediante su manifestación disminuyen por el solo transcurso de la vida, sin perjuicio de que deterioros de estos tipos se dan frecuentemente en los ancianos". Esta decisión judicial resalta la importancia de distinguir la "senectud" o simple ancianidad -envejecimiento normal- de la "senilidad patológica" o calificada como senilidad.

Esta última daría lugar a la interdicción o inhabilitación -en términos del CCA-, o a la restricción de la capacidad, la incapacidad y la inhabilitación previstas en el nuevo ccca. Los prejuicios que imperan en torno a la vejez han contribuido a la asociación de esta etapa de la vida con el deterioro físico y mental. En este punto, consideramos que la CDPD, al establecer en el artículo 2 una serie de definiciones, colaborará sin duda a desterrar el binomio vejez-discapacidad. Respecto al proceso de "envejecimiento", la Convención entiende que se trata de un "proceso gradual que se desarrolla durante el curso de vida y que conlleva cambios biológicos, fisiológicos, psico-sociales y funcionales de variadas consecuencias, las cuales se asocian con interacciones dinámicas y permanentes entre el sujeto y su medio". A la vez que deja en claro que el concepto de vejez es una construcción social.

Por suerte, esta misma consideración fue continuada en el año 2009, en el caso "S., L. F.; D., F. y P. s/ incapacitación”. Allí, la sentencia vuelve a poner de resalto de manera ejemplar que la vejez por sí sola no puede convertirse en

56 Cámara Nacional Civil de Buenos Aires, Sala D, junio 22-1982, La Ley I 983-A, 3 I 3-3 16.

57 Méndez Costa, M. J., Los ancianos en la legislación civil, Buenos Aires, La Ley, I983, 3 I 2. 
causal de inhabilidad o insania. En este caso, la justicia de grado desestimó la demanda de inhabilitación solicitada por la hija de un hombre de noventa años fundada en las grandes sumas de dinero que su padre gastaba en su vida cotidiana. La Cámara consideró que "el hecho de que pretenda disponer de una suma considerable de dinero mensualmente para sus gastos no configura un acto de absurdo en el manejo de sus negocios y finanzas, en tanto no es irracional que pretenda tener un estándar de vida sin sobresaltos mientras no comprometa su capital ni absorba la totalidad de sus utilidades. Por último, resalta que las dolencias y afecciones propias de la edad avanzada no pueden convertirse por sí solas en fuente de disminución de la capacidad civil" $5^{8}$.

En el año 20 Io se dictó otro fallo emblemático sobre esta materia, en "E. de R., N. s/ incapacitación”. En el caso, un hijo solicitó la interdicción de su madre, alegando una patología debido a la supuesta dilapidación de sus bienes. En primera instancia se rechazó el pedido y la Cámara confirmó aquella sentencia. Los jueces argumentaron que en la mujer no se verificaba patología alguna y que tampoco se había logrado demostrar de modo fehaciente la dilapidación de bienes propios que se invocaba como síntoma de demencia. En este sentido, la Cámara enfatizó que "la ancianidad como proceso fisiológico normal, no excluye la salud. No puede entenderse, entonces, que no gozan de ella personas en quienes la ciencia médica no registra modos de ser anormales en relación con su edad. El temor de que el anciano no haga buenos negocios, como cualquier persona, no tiene su remedio en la inhabilitación, si ello no resulta de un estado patológico" 59 .

\section{B. Importancia del contacto personal de los jueces con la persona en cuestión durante la tramitación del juicio}

Un ejemplo relevante de buena práctica jurisprudencial sobre la importancia del contacto personal de los jueces con el presunto inhabilitado lo constituye el fallo de la Cámara Nacional Civil, Sala G, de 4 de diciembre de i98o, en " $M$. M.P. de V. s/ inhabilitación”. Aquí, por primera vez, se reconoce enfáticamente la importancia del contacto personal del juez con el presunto incapaz o inhábil como clara garantía del derecho de defensa y del derecho a ser oído de toda persona mayor $^{60}$. En este caso, un hijo pretendía la declaración de inhabilidad de su madre añosa, fundado en la disminución psíquica de esta como consecuencia de su avanzada edad (art. I 52 bis inc. $2^{\circ}$ ) y en su supuesta prodigalidad (art. I 52 bis inc. $\left.3 \cdot^{\circ}\right)$.

$5^{8}$ Cámara Apelaciones Civil y Comercial de Junín, 22/o9/2009, S., L. F., D F y P, La Ley, enero, 20IO, 2 I4.

59 Cámara Nacional Civil, Sala, o I/o6/2004, E. de R., N., La Ley I8/o8/2004, Iо.

60 Cámara Nacional Civil, Sala G, o4/ı2/ı 980, M.P. de V., M., La Ley I98 I-B, 26. 
El juez de cámara tomó contacto personal con la demandada en varias ocasiones. Constató así de manera directa que la mujer conservaba intactas las facultades mentales para poder seguir llevando adelante actos de la vida cotidiana sin necesidad de un curador, de modo tal que desestimó la demanda y no otorgó credibilidad a las conclusiones de la pericia médica que daban cuenta de lo con$\operatorname{trario}^{6 \mathrm{I}}$.

Este fallo fue visionario de lo que sería, casi treinta años después, el desarrollo del nuevo paradigma de la discapacidad, contemplado en la CDPD y en el cccA. El magistrado, luego de mantener entrevistas personales con la anciana, desestima las conclusiones de los peritos médicos y arriba a la conclusión de que la presunta insana puede seguir llevando adelante actos de su vida cotidiana sin necesidad de un curador. El magistrado apoya esta decisión advirtiendo que la anciana se había rodeado de personas de su confianza a fin de delegarles determinados asuntos de mayor complejidad -adelantándose así a la noción actual de la figura de los apoyos, contemplada en la CDPD, la Ley de Salud Mental 26657 y el cCCA, así como en la recientemente aprobada CIDHPM (art. $3^{[62]}$ ).

\section{Gradualidad de las restricciones a la capacidad}

Acerca de la necesidad de graduar las restricciones a la capacidad, esta ya venía dictaminándose desde 1985 , tal como se acredita en emblemático fallo de la Cámara Nacional de Civil Apelaciones, Sala C, de I 2 de agosto de I985, en el caso "J.L. del V. s/ inhabilitación"63. En este juicio se subrayó la necesidad de contemplar la gradualidad de las incapacidades, no restringiendo las aptitudes de la persona más allá de lo estrictamente necesario, y siempre en miras de su protección. Así, en este caso sobre rehabilitación del insano se puso de relieve que en cada fallo es posible establecer los actos que la persona puede realizar y aquellos que no está en condiciones de asumir. La justicia se expidió de esta manera ante una petición realizada por la directora de la clínica psiquiátrica donde se encontraba internado el declarado incapaz. La directora solicitó autorización al juez para que el incapaz pudiese ser empleado contratado del establecimiento que ella dirigía, argumentando y probando los beneficios que esa actividad laboral reportaría para aquel.

Los jueces de la Cámara resolvieron favorablemente a la petición, argumentando que la declaración de incapacidad de una persona no puede basarse exclu-

6I El magistrado tuvo una entrevista personal con la anciana, en la cual la variedad de temas tratados, la amenidad y riqueza de sus expresiones, la coherencia de sus manifestaciones rechazaban terminantemente la idea de que se tratara de un débil de espíritu. Ver Cámara Nacional Civil, Sala G, diciembre 4-1980, La Ley, Buenos Aires, I98 I-B, 23-36.

62 Ver art. 30 CADPM (2OI5).

63 Cámara Nacional de Civil Apelaciones, Sala C, r2/08/1985, Del V., J. L., La Ley r 985 -E, 47. 
sivamente en razones médicas, pues "no es posible menospreciar la historia de vida del incapacitado, ni los relieves de su medio social inmediato. Si un enfermo mental crónico en proceso de rehabilitación y resocialización, no está en condiciones de casarse, de vivir solo, de reconocer hijos, de vender bienes, etc., pero sí está en condiciones de trabajar como cadete en la clínica donde está internado, de recibir un sueldo y de administrarlo, sin ningún riesgo, y no se le permite hacerlo, la protección se transforma en represión enfermante, en frustración de una recuperación" 64 .

En una postura semejante a la que inspiró el fallo anteriormente citado se inscribe el caso "L., C. y otros s/ incapacitación"65. El curador de una persona declarada incapaz acude a la justicia para solicitar que se autorice al interdicto para manejar pequeñas sumas de dinero, provenientes de su pensión. La cámara concluyó que "si la finalidad primordial de la curatela radica en que la persona declarada incapaz recupere su capacidad o que pueda gobernar su persona y administrar sus bienes, no puede ignorarse la decisiva importancia que tiene la posibilidad de que maneje por sí los ingresos que percibe"66.

En estos precedentes encontramos un ejemplo del beneficio que significó para la persona lograr una sentencia que marcara claramente la extensión de la medida limitativa de la capacidad. Tres décadas después, el espíritu de estas sentencias puede verse reflejado en una legislación que contempla la regla de que las declaraciones judiciales que restrinjan la capacidad deberán especificar las funciones o actos que se limitan -conforme se establece en la CDPD, la Ley de Salud Mental y el cccA.

La сіDнрм se inscribe en esta concepción al prever, en el artículo 30 :

... los Estados Parte reconocerán que la persona mayor tiene capacidad jurídica en igualdad de condiciones con los demás en todos los aspectos de su vida. Los Estados parte adoptarán las medidas pertinentes para proporcionar acceso a la persona mayor al apoyo que puedan necesitar en el ejercicio de su capacidad jurídica. Además, las salvaguardias deberán ser proporcionales y adaptadas a las circunstancias de la persona mayor, que se apliquen en el plazo más corto posible y que estén sujetas a exámenes periódicos por parte de una autoridad o un órgano judicial competente, independiente e imparcial.

El artículo reseñado finaliza conminando a los Estados parte a tomar las medidas pertinentes para garantizar el derecho de las personas mayores, en igualdad de

64 Cámara Nacional de Civil Apelaciones, Sala C, I2/08/1985, Del V., J. L., La Ley 1985-E, 47.

65 Cámara Nacional Civil, Sala G, o2/o9/20 Io, C., L. y otros s/ insania, El Dial.com, año xIII, n. ${ }^{\circ}$ $3 \mathrm{I} 38$.

66 Cámara Nacional Civil, Sala G, o2/o9/20 Io, C., L. y otros s/ insania, El Dial.com, año xIII, n. ${ }^{\circ}$ $3 \mathrm{I} 38$. 
condiciones con los demás, a ser propietarias y controlar sus propios asuntos económicos y a velar por que no sean privadas de sus bienes de manera arbitraria.

\section{Sobre curatela compartida}

En materia de representación compartida es posible recordar algunos fallos, tratados en estudios anteriores ${ }^{67}$. En ellos, lo novedoso consistió en la habilitación de la posibilidad de designar a dos curadores conjuntos para garantizar un mejor cuidado de la persona y de los bienes del incapaz. Avance revolucionario si se considera la rigidez que hasta el nuevo ccca tenía el régimen argentino respecto de la curatela única ${ }^{68}$.

La mayoría de estos casos resueltos en este campo se refieren a padres que desean ser curadores de sus hijos, y también se incluyen los referidos a hermanos que quieren asumir la curatela del insano, o a hijos que cuidan de los padres en situación de discapacidad. Así, en un fallo muy interesante del año 20 I I, "L., A. D. s/ insania" de una persona, su hermana y su madre solicitan judicialmente ejercer la curatela de manera conjunta. Señalaron que el ejercicio de la curatela estaba en cabeza de la madre que ya contaba con una muy avanzada edad, lo que generaba el peligro inminente de poner en riesgo la vida y el patrimonio del insano a causa de los problemas de salud que ella comenzaba a manifestar. Tampoco querían que el insano se quedara sin curador oficial en el ínterin, situación que colocaba en estado de indefensión al incapaz.

La justicia se hizo eco de la petición y otorgó la curatela conjunta. Argumentó que la normativa del código civil velezano en relación con las personas con discapacidad resulta en muchos casos opuesta al bloque de constitucionalidad (art. 75 inc. 22), así como con la promoción del goce efectivo de las normas contenidas en ellos (art. 75 inc. 23), y procede a declarar la inconstitucionalidad de las normas que se oponen al pedido de las actoras. Así, concluye diciendo que "la solución propuesta satisface la finalidad tuitiva de la curatela de incapaces, que es la de garantizar el derecho a la salud y al mejor nivel de vida posible del incapaz, derechos de raigambre constitucional" "99. Afortunadamente, ahora el cccA contempla la posibilidad de designación de una o más personas para que le presten apoyo a la persona con discapacidad (art. 36).

67 Daвove et al., "La ancianidad y la salud mental. El régimen legal argentino sobre incapacidad y necesidad de reformas", en Envejecimiento, memoria colectiva y construcción de futuro. Memorias del II Congreso Iberoamericano y I Congreso Uruguayo de Psicogerontología, Montevideo, Universidad de la República del Uruguay, 2007, 533-541.

68 En relación con la curatela conjunta véase Lloveras y Monjo, S., "La curatela, ¿compartida?", Actualidad furídica de Córdoba, año III, vol. 46, febrero, 2008, 4929.

69 "L., A. D. s/ curatela", Cámara Civil y Comercial de Mar del Plata, Sala 3. ${ }^{a}, 24$ de febrero de 201 I (Lexis n. ${ }^{\circ}$ 70068I 78 ). 
Con relación a buenas prácticas judiciales del derecho argentino posteriores a la Convención Internacional de Derechos de las Personas con Discapacidad es posible resaltar, al menos, tres casos, dos del año 20 I 2 y otro de 2014.

El I 2 de junio de 2012, la Corte Suprema de Justicia de la Nación resolvió un caso relativo a la capacidad jurídica de una persona de 90 años multimillonaria, en el cual reconoció la distinción antes aludida entre senectud y senilidad patológica ("B., J.M. s/ insania”). Pero además señaló por primera vez que son aplicables la CDPD, la Convención Interamericana sobre Eliminación de Todas las Formas de Discriminación y la Ley de Salud Mental, instrumentos todos que tienen como eje no solo el reconocimiento del ejercicio de la capacidad jurídica, sino también la implementación de mecanismos de apoyo, salvaguardas y ajustes razonables tendientes a que quienes están afectados por estos padecimientos puedan ejercer esa capacidad jurídica en iguales condiciones que los demás.

Ese año, en el caso “C.M. s/ Artículo I 52 ter CC”, un juez de primera instancia revisó la sentencia de insania de una mujer anciana y resolvió inhabilitarla al advertir que su estado había mejorado y que tenía más autonomía. Con aplicación de la Convención sobre los Derechos de las Personas con Discapacidad, resolvió que a partir de ese momento la persona solo necesitaría de su curador para administrar sumas importantes de dinero, aclarando que el curador no representa ni sustituye la voluntad sino que "acompaña" las decisiones de la persona en los asuntos patrimoniales señalados (Juzgado Nacional en lo Civil n. ${ }^{\circ} 7$, “C., M. s/I Artículo I 52 ter Código Civil”, exp. 99.247/I996, I8/o6/20 I 2).

Más recientemente, el ıo de abril de 2014, una jueza de primera instancia rehabilitó a una mujer anciana de 86 años, en el caso "M., D.N. s/ inhabilitación". Hasta ese momento la mujer había sido inhabilitada. La jueza tomó la decisión por petición de la curadora pública de la anciana, quien advirtió que esta conducía su vida en forma totalmente autónoma. Nuevamente, en aplicación de la Convención sobre los Derechos de las Personas con Discapacidad, se resolvió eliminar las restricciones a la capacidad jurídica que, frente a una notable mejoría del estado de salud de la persona, resultaban innecesarias y hasta podían serle inconvenientes. Destacó que no había ningún motivo que justificara continuar con un proceso que arrojaba un manto de sospecha sobre la aptitud de una persona cuyas facultades mentales no presentaban ninguna alteración (Juzgado Nacional en lo Civil n. ${ }^{\circ}$ 88, "M., D. N. s/ Inhabilitación, exp. 91.850/2006, Io/04/20 I4).

Por último, cabe advertir que son muy pocas las sentencias argentinas específicamente referidas a la capacidad jurídica de las personas adultas mayores posteriores al ccc. Sin embargo, entre ellas adquiere relevancia el fallo "S. O. s/ insania", n. ${ }^{\circ}$ 202/I 5, del Juzgado de Primera Instancia en lo Civil, Comercial y Laboral de la Secretaría n. ${ }^{\circ}$ I de Corrientes (de I 8 de agosto de 20I5). En este caso, el Tribunal rechazó in limine la demanda dirigida a la designación de un curador destinada a la obtención de beneficios asistenciales derivados de la pensión correspondiente. Entendió que, en el marco del código civil y comercial, la de- 
claración de incapacidad quedó claramente reducida a casos excepcionalísimos, en los cuales la persona se halla absolutamente imposibilitada de interactuar con su entorno y de expresar su voluntad por cualquier medio y modo. Pero, además, destacó que para someter una persona al trámite judicial de declaración de su incapacidad o de capacidad restringida conforme el artículo $35 \mathrm{ccc}$, debe darse inicio al trámite mediante una demanda idónea y objetivamente proponible.

Ahora bien, estos criterios fueron continuados en los autos caratulados "C. A. R. s/determinación de la capacidad" de la Cámara Nacional Civil, Sala H, de 22 de diciembre de 20r6. En efecto, si bien el fallo no es significativo en cuanto a las cuestiones planteadas en la litis -ya que se trató de una sentencia rectificatoria de un error material en la calificación de la restricción a la capacidad-, adquiere importancia debido a la posición que sienta en esta materia.

En este marco, el tribunal enfatizó:

... toda restricción a la capacidad debe serlo en la medida necesaria y apropiada para el bienestar (cfr. art. r. ${ }^{\circ}$ de la Convención Interamericana para la Eliminación de Todas las Formas de Discriminación contra las Personas con Discapacidad, aprobada por la Ley 25.280), proporcional y adaptada a las circunstancias de cada persona, y sujeta a exámenes periódicos (cfr. art. I 2 de la Convención sobre los Derechos de las Personas con Discapacidad, aprobada por Ley 26.378, art. 37 del código civil y comercial de la Nación; cNciv. Sala "G", r. 5 I6.729 del I5-4-2009; r. 560.304 del 2-9-20Iо; r. 566.84I del 24-II-20Iо; r. 569.864 del 3O-I2-2OIO; r. 585.328 del 2I/9/2OII).

También, señala que en virtud de la entrada en vigencia de la nueva normativa en el ámbito civil (arts. 37, 38, 39, 43 ss. ccc), son de obligatorio cumplimiento "las disposiciones previstas a los fines de decidir un régimen en el que se tienda a incentivar la autonomía del interesado en cuanto resulte posible. Entre otras razones, toda vez que la mencionada normativa ha tomado las previsiones de la Ley de Salud Mental (26.657) en cuanto busca evitar generar mayores dependencias o restricciones de las que el padecimiento pueda generarle a la persona interesada, y así lograr mantener o incrementar la autonomía personal, si es que la tiene, incentivando su desarrollo".

Así, pues, cabe inferir que, con el tiempo, esta línea jurisprudencial se expandirá y permitirá resolver los casos de este campo sin prejuicios "edadistas" o "viejistas", distorsivos de la dignidad de los adultos mayores.

\section{Reflexiones finales}

En este trabajo se ha abordado la problemática de la autonomía y los cuidados de las personas mayores en situación de dependencia a partir de dos supuestos: el desarrollo del envejecimiento poblacional que hoy, además de ser global, es 
multigeneracional, por un lado, y la necesidad de consolidar el derecho de la vejez, por otro. Conforme a ello, se definió la autonomía como "aquel espacio individual en cuyo ámbito cada persona ejerce por sí misma el poder sobre su vida y su patrimonio, establece reglas, disposiciones o planes que sólo a él se refieren y le permiten proyectarse y desarrollarse, en igualdad de condiciones -aunque sin dañar- que los demás". En el derecho actual, la capacidad es un factor constitutivo de la autonomía personal.

Históricamente, la autonomía fue concebida en atención a un concepto de persona abstracto y universal. En la actualidad, esta perspectiva ya no puede sostenerse de manera consistente. El envejecimiento global y multigeneracional ha puesto todo esa concepción en crisis, así como también ha dado lugar al reconocimiento de la "gerontolescencia". Una nueva expresión de la crisis de identidad que las personas mayores padecen, a raíz de la cultura ambivalente sobre la vejez.

En Argentina las personas adquieren capacidad jurídica plena (de derecho y de obrar) al cumplir los i 8 años, la cual, una vez obtenida, no se pierde por el simple transcurso del tiempo. Solo causas graves, o situaciones que pongan en riesgo su vida o patrimonio, pueden dar lugar al establecimiento de restricciones a la capacidad, respecto de las cuales los jueces son los únicos habilitados para pronunciarse. Así, pues, la capacidad continúa siendo "regla", incluso para la persona envejecida. Sin embargo, a partir del año 2007 la incorporación de la Convención sobre los Derechos de las Personas con Discapacidad introduce un giro copernicano en esta materia, esto al reforzar aún más la regla de la capacidad plena (art. I 2); al rechazar categóricamente cualquier restricción a la capacidad jurídica que implique la sustitución de voluntad; al obligar a los Estados a garantizar sistemas de apoyos y salvaguardias para las casos en que las personas requieran mecanismos que restrinjan su capacidad, en alguna medida (art. I2); al introducir, en suma, el modelo social explicativo de la discapacidad.

El derecho argentino ha adaptado el nuevo paradigma de la CDPD tanto por su jerarquía constitucional (art. 75 inc. $22 \mathrm{cN}$ ) como por lo estipulado en el mismo artículo I ccca. Se estudió esta evolución y su incidencia en la regulación jurídica de las pruebas de los deterioros cognitivos y en la propia curatela. Se observó que el proceso de flexibilización del régimen de la curatela favoreció su reconocimiento como instrumento de apoyo para la toma de decisiones con protección de las personas con discapacidad, conforme al modelo social de la Convención. Pero, además, se determinó que los casos judiciales sobre determinación de capacidad jurídica de las personas mayores más frecuentes van asociados a los deterioros cognitivos. Aunque en una escala menor traen causa también de los supuestos de prodigalidad, alcoholismo o adicciones.

La ciDHPM ha captado algunos aspectos que hemos desarrollado en este trabajo, atendiendo a las particularidades que se derivan del envejecimiento global y multigeneracional, como podemos observar en el preámbulo al reconocer que "la persona, a medida que envejece, debe seguir disfrutando de una vida plena, 
independiente y autónoma, con salud, seguridad, integración y participación activa en las esferas económica, social, cultural y política de sus sociedades".

En el tema puntual de la capacidad de las personas mayores, la Convención Interamericana contiene los siguientes avances:

a. Logra un reconocimiento pleno de la autonomía personal en la vejez ${ }^{70}$.

b. Establece un régimen de capacidad que evita ser restringido generalizadamente $^{7 \mathrm{I}}$, tal como lo propone la CDPD.

c. Promueve la inclusión de mecanismos que contemplen sistemas de apoyo con salvaguardias para las personas mayores cuyo discernimiento, libertad o intención se vean afectados negativamente y, sistema de representación en forma excepcional para las personas mayores que no hayan podido comunicar su voluntad por ningún medio ${ }^{72}$.

d. Fomenta la adopción del criterio de gradualidad a la hora de establecer las restricciones para el caso.

La Convención Interamericana es, pues, muy importante ya que completa el paradigma de la CDPD en materia de autonomía y capacidad jurídica.

Por último, en materia de autonomía y capacidad consideramos necesario que la futura Convención Internacional de Derechos Humanos de las Personas Mayores, actualmente en discusión en la onu, logre:

a. Rediseñar la curatela en función del paradigma actual de los cuidados en la vejez, implementando jurídicamente: sistemas de "decisiones asistidas" y el asistente personal; el reconocimiento y la protección de las redes familiares y afectivas; los apoyos entre pares; las medidas de accesibilidad que maximicen el trato igualitario y la inclusión 73 .

b. Contemplar la posibilidad de imponer la obligación judicial de distinguir la vejez normal de la patológica (senilidad) con base en pericias interdisciplinarias.

c. Promover el deber de tomar contacto personal con el presunto incapaz por parte de los jueces.

d. Incorporar al sistema jurídico las disposiciones anticipadas, registradas en instrumentos públicos o privados fehacientes, a fin de tomar conocimiento de la voluntad de la persona mayor en esta materia ${ }^{74}$.

Art. 7 CADPM. Derecho a la independencia y a la autonomía ( ${ }^{\mathrm{e}}{ }^{\mathrm{er}}$ párr.).

Art. 30 CADPM. Igual reconocimiento como persona ante la ley ( $\mathrm{I} .{ }^{\mathrm{er}}$ y $2 .{ }^{\circ}$ párrs.).

Art. 30 CADPM. Igual reconocimiento como persona ante la ley $\left(3 \cdot{ }^{\mathrm{er}} \cdot \mathrm{y} 4{ }^{\circ}{ }^{\mathrm{o}}\right.$ párrs.).

Seguimos en este punto la propuesta de Álvarez Ramírez y Villarreal Arroyo, ob. cit.

La CDPD contempla la figura de las disposiciones anticipadas solamente en materia de salud; art. I I CADPM. 


\section{Bibliografía}

Álvarez Ramírez, E. M. y Villarreal Arroyo, M., "Análisis de la curatela y la capacidad de actuar de las personas con discapacidad en Costa Rica, a la luz de la Convención sobre los Derechos de las Personas con Discapacidad”, tesis de licenciatura en Derecho, San José, Universidad de Costa Rica, 20 ıo, disponible en: http://iij.ucr.ac.cr/sites/default/files/documentos/tıo- analisis_de_la_curatela_y_capacidad_de_actuar_de_personas_discapacitadas.pdf [Consultado el I 5 de abril de 20r4].

BACH, M., "El derecho a la capacidad jurídica en la Convención de la onu sobre los Derechos de las Personas con Discapacidad: conceptos fundamentales y lineamientos para una reforma legislativa", en Palacios, A. et al., Capacidad jurídica, discapacidad y derechos humanos: una revisión desde la Convención Internacional sobre los Derechos de las Personas con Discapacidad, Buenos Aires, EDiar, 20I 2, 55-IO7.

Cifuentes, S., Negocio jurídico, 2. ${ }^{\mathrm{a}}$ ed., Buenos Aires, Astrea, 2004.

Ciuro Caldani, M.Á., La conjetura del funcionamiento de las normas jurídicas: metodología jurídica, Rosario, Fundación para las Investigaciones Jurídicas, 2000.

Ciuro Caldani, M. Á., Metodología jurídica y lecciones de bistoria de la filosofía del derecho, Rosario, Zeus, 2007.

Ciuro Caldani, M.Á., Estrategia jurídica, Rosario, unr Editora, 20 I I.

Clusellas, G. et al., Código civil y comercial. Comentado, anotado y concordado. Modelos de redacción sugeridos, t. I, Buenos Aires, Astrea, 2015.

Cuenca Gómez, P., "La configuración de los apoyos", Conferencia ALFA: Discriminación y grupos en situación de vulnerabilidad: género y discapacidad, Instituto de Derechos Humanos "Bartolomé de las Casas" (Universidad Carlos III de Madrid, Lima, Perú, 2 a 4 de septiembre, 20 I4), disponible en http://idehpucp.pucp.edu.pe/wp-content/uploads/20 I 4/o9/La-configuraci $\% \mathrm{C}_{3} \% \mathrm{~B}_{3} \mathrm{n}$ de-los-apoyos-Patricia-Cuenca.pdf [Consultado el 30 de marzo de 20 I 5].

Daвove, M. I., Los derechos de los ancianos, Buenos Aires, Ciudad Argentina, 2002.

Daвove, M. I., "Derecho y multigeneracionismo: o los nuevos desafíos de la responsabilidad jurídica familiar en la vejez", Revista de Derecho de Familia, n. ${ }^{\circ} 40$, julio/agosto, 2008, 39-54. 
Dabove, M. I., "Autonomía y atención de las personas mayores en situación de dependencia en España: una cita entre generaciones", Oñati Socio-Legal Series, vol. I, n. ${ }^{\circ} 8,20 \mathrm{I}$, 3-27.

Dabove, M. I., "Voluntad, capacidad y derechos fundamentales en la vejez: el problema cotidiano de la autonomía jurídica frente al envejecimiento”, en Bariffi, F. y Palacios, A., Capacidad jurídica, discapacidad y derechos bumanos, Buenos Aires, EDIAR, 20I 2, 36I-384.

Dabove, M. I., "Elder Law: A need that emerges in the course of life", Ageing International, September 20I 3, I38-I48. DoI: IO. IOO7/s I 2 I 26-OI 3-9I93-4.

Daвove, M. I. et al., Derechos humanos de las personas mayores: acceso a la justicia y protección internacional, Buenos Aires, Astrea, 2015.

Dавоve, M. I. et al., "La ancianidad y la salud mental. El régimen legal argentino sobre incapacidad y necesidad de reformas", en Envejecimiento, memoria colectiva y construcción de futuro. Memorias del II Congreso Iberoamericano y I Congreso Uruguayo de Psicogerontología, Montevideo, Universidad de la República del Uruguay, 2007, 533-54I.

Dabove Caramuto, M. I. y Prunotto Laborde, A. (dirs.), Derecho de la ancianidad: perspectiva interdisciplinaria, Rosario, Juris, 2006.

Dayton, K., Comparative Perspectives on Adult Guardianship, Durham, Carolina Academic Press, 20I4, 247-27I.

Di Tullio Budassi, R., "La evolución legislativa y jurisprudencial en materia de salud mental referida a la vejez: perspectiva en el derecho proyectado", Derecho de Familia. Revista interdisciplinaria de doctrina y jurisprudencia, n. ${ }^{\circ}$ 56, septiembre, 20I 2, 23-37, disponible en: http://scm.oas.org/ag/documentos/ [Consultado el i 5 de agosto de 20 I 5].

Fernández, S., "Ancianidad, autonomía y vulnerabilidad. Una mirada a la situación jurídica de los adultos mayores desde la reforma proyectada para el código civil argentino", Revista Derecho Privado, año I, n. ${ }^{\circ}$ 2, Buenos Aires, Infojus, 201 2, I 39-163.

Fernández Mele, S. y Goizueta, M. P., “Ancianidad e insania, comentario a fallo 'N. H. en nombre y representación de L. M. L. s/ curatela', Superior Tribunal de Justicia de Corrientes del 22/Ir/20r2", Revista de Derecho de Familia, vol. de jurisprudencia III/2013, I30-I44. 
Frolik, L. y Kaplan, R., Elder Law, 3. ${ }^{\text {a }}$ ed., St. Paul, Thompson West, 2003.

Garrido Cordobera, L. et al., Código civil y comercial argentino. Comentado, anotado y concordado, t. I, Buenos Aires, Astrea, 20 I 5.

Goldschmidt, W., Introducción filosófica al derecho: la teoría trialista del mundo jurídico y sus horizontes, 6. ${ }^{\mathrm{a}}$ ed., Buenos Aires, Depalma, I987.

Herrera Ponce, M. S. et al., "Estigmas en torno a las demencias y las implicancias en el cuidado de patologías demenciales de las personas mayores", en Kornfeld Matte, R.; Fernández Lorca, M. B. y Belloni Symon, C. L. (eds.), Personas mayores y demencias: realidad y desafíos, Santiago de Chile, Pontificia Universidad Católica de Chile, 20 I 5.

Iacub, R., Identidad y envejecimiento, Buenos Aires, Paidós, 20 I I.

Instituto Nacional de Estadística y Censos [Argentina], Encuesta nacional sobre calidad de vida de adultos mayores 2012 , ENCaViAM: principales resultados, 20I3, disponible en: http://www.indec.gov.ar/ftp/cuadros/sociedad/encaviam.pdf [Consultado el i 5 de septiembre de 20I4].

Kalache, A., "Entrevista”, La Nación, I4/ıo/ı3. Disponible en: http://www. lanacion.com.ar/ I6290 I 7-alexandre-kalache-estamos-creando-una-nuevaetapa-de-la-vida-que-antes-no-existia-yo-lo-llamo-gerontolescencia [Consultado el i 5 de agosto de 20 I 5 ].

Kant, I., La metafísica de las costumbres, A. Cortina y J. Conill Sancho (trad. y notas), Madrid, Tecnos, I989.

Kant, I., Crítica de la razón práctica, J. Rovira Armengol (trad.), 5. ${ }^{a}$ ed., Buenos Aires, Losada, I990.

Lesson, G., "Demography, politics and policy in Europe”, en Ludow, P. (ed.), Setting EU Priorities 2009, The European Strategy Forum, Ponte de Lima, Portugal, 2009, IO2-I 24.

Lesson, G., "Future ageing in Southeast Asia: Demographic trends, human capital and health status", en Nurvidya, E. y Ananta, A. (eds.), Older persons in Southeast Asia, Institute of Southeast Asian Studies (ISEAS), Singapore, 2009, $47-67$. 
Lesson, G., "Prepared or not, Latin America faces the challenge of aging, current history", fournal of Contemporary World Affairs, vol. I Iо, n. ${ }^{\circ} 733$, 201 I, $75^{-8}$ o.

Lloveras, N. y Monjo, S., "La curatela, ¿compartida?”, Actualidad Furídica de Córdoba, año III, vol. 46, febrero, 2008.

Méndez Costa, M. J., Los ancianos en la legislación civil, Buenos Aires, La Ley, I983.

Naciones Unidas, CEPAL, El envejecimiento y las personas de edad: indicadores sociodemográficos para América Latina y El Caribe, 2009. Disponible en: http:// www.cepal.org/es/publicaciones/I 350-el-envejecimiento-y-las-personasde-edad-indicadores-sociodemograficos-para [Consultado el 20 de abril de 20I5].

Olmo, J. P., Salud mental y discapacidad, Buenos Aires, Dunken, 20 I4.

Olmo, J. P., Salud mental y discapacidad: adenda de actualización, Buenos Aires, Dunken, 2016.

Olmo, J. P., Salud mental y discapacidad: análisis del código civil y comercial de la Nación, Buenos Aires, Dunken, 2017.

oms, Informe Mundial sobre el Envejecimiento y la Salud, 2015, disponible en: http://www.who.int/ageing/publications/world-report-2015/es/ [Consultado el ro de abril de 2015].

Palacios, A., El modelo social de discapacidad: orígenes, caracterización y plasmación en la Convención Internacional sobre los Derechos de las Personas con Discapacidad, Madrid, Caja Madrid, 2008.

Rajmil, A. B. y Llonens, L. R., "Apuntes acerca del régimen de capacidad de las personas humanas en el código civil y comercial de la República Argentina (Ley 26.994)", IUs. Revista del Instituto de Ciencias furídicas de Puebla, año Ix, n. ${ }^{\circ} 6$, julio-diciembre 20 I 5,89 -I I 7 .

Rio Declaration, “Beyond Prevention and Treatment: Developing a Culture of Care in response to the Longevity Revolution", I 3 de octubre de 20 I3. Declaration signed by the International wDA Forum (Rio de Janeiro Oct. I6-I 7 2OI3), an initiative by the International Longevity Centre-Brazil (ILC-BR) and the World Demographic \& Ageing Forum (wDA Forum), co-organized 
by Bradesco Seguros and UniverSeg in association with the Centro de Estudo e Pesquisa do Envelhecimento (CEPE) and partners from academia, government, civil society organizations and the United Nations.

Roqué, M., "El camino de la comunidad internacional”, en Dabove, M. I. (dir.), Derechos humanos de las personas mayores: acceso a la justicia y protección internacional, Buenos Aires, Astrea, 201 5, 67-73.

Тові́́s, J. W., “Capacidad. Inhabilitación judicial. La causal del inciso $2 .^{\circ}$ del artículo I 52 bis. Ámbito”, en ТовíAs, J. W., Colección de análisis jurisprudencial derecho civil: Parte general, Buenos Aires, La Ley, 2003.

Тові́as, J. W., Derecho de las personas, Buenos Aires, La Ley, 2009.

United Nations, Committee on the Rights of Persons with Disabilities, Concluding observations on the initial report of Argentina as approved by the Committee at its eighth session ( 1 7-28 September 2012 ), disponible en: http://www. refworld.org/docid/54993c374.html [Consultado el 20 de abril de 20 I 5].

United Nations, Committee on the Rights of Persons with Disabilities, I I ${ }^{\text {th }}$ Session, 3 I March-I I April 20I4. General comment n. ${ }^{\circ}$ I (20I4) I, Article r 2: Equal recognition before the law, disponible en: http://daccess-ddsny.un.org/doc/Undoc/GEN/Gi4/O3 I/20/PDF/GI4O3 I 20.pdf? OpenElement [Consultado el I I de julio de 20I 5 ].

Zannoni, E. A., Ineficacia y nulidad de los actos jurídicos, Buenos Aires, Astrea, 2013.

Zannoni, E. A. et al., Código civil y comercial. Concordado con el régimen derogado y referenciado con legislación vigente. Exégesis de los fundamentos de la Comisión redactora y las modificaciones del PEN, Buenos Aires, Astrea, 2015.

\section{Normas citadas}

Ley 340 (29/o9/r869), Código civil de la Nación [Argentina], disponible en: http://www.infoleg.gov.ar/infolegInternet/anexos/I05000-I09999/I0948I/ texact.htm [Consultado el i I de julio de 2015].

Ley 26994 (Io/ro/20I4), Código civil y comercial de la Nación [Argentina], disponible en: http://www.infoleg.gob.ar/infolegInternet/anexos/235000239999/235975/norma.htm [Consultado el i I de julio de 20 I 5]. 
oea, Asamblea General, Convención Interamericana sobre la Protección de los Derechos Humanos de las Personas Mayores (СіDHрм), 20 5 . Disponible en: http://www.oas.org/es/sla/ddi/docs/tratados_multilaterales_interamericanos_A-70_derechos_humanos_personas_mayores.pdf [Consultado el i I de julio de 2015].

onu, Asamblea General, Convención de Viena sobre el Derecho de los Tratados, I969-I980, disponible en: http://www.wipo.int/export/sites/www/ wipolex/es/glossary/vienna-convention-es.pdf [Consultado el ro de julio de 20I5].

onu, Asamblea General, Resolución 46/9i, Principios de las Naciones Unidas en Favor de las Personas de Edad: adoptados por la Asamblea General de las Naciones Unidas el i6 de diciembre de r99ı. Disponible en: http://www. acnur.org/t3/fileadmin/scripts/doc.php?file=t3/fileadmin/Documentos/ $\mathrm{BDL} / 2003 / \mathrm{I} 640$ [Consultado el ro de diciembre de 20 I4].

onu, Asamblea General, Convención de Derechos de las Personas con Discapacidad, 2006, disponible en: http://www.un.org/esa/socdev/enable/documents/tccconvs.pdf [Consultado el i I de julio de 20 I 5].

onu, Comité sobre los Derechos de las Personas con Discapacidad, Observación general n. ${ }^{\circ}$ I [sobre el] Artículo I 2: Igual reconocimiento como persona ante la ley. i i ${ }^{\text {er }}$ período de sesiones, 3 I de marzo a i I de abril de 20 I4, disponible en: http://daccess-dds-ny.un.org/doc/UnDoc/GEN/Gi4/O3I/23/ PDF/Gi403 I 23.pdf? OpenElement [Consultado el 9 de mayo de 20 I 5].

\section{Jurisprudencia citada}

Fallo de la Cámara Nacional Civil, Sala G, 4 de diciembre de i98o, La Ley, I $98 \mathrm{I}-\mathrm{B}, 23-36$.

Fallo de la Cámara Nacional Civil, Sala D, 22 de mayo de I982, La Ley I983-A, 3 $13-3$ I6.

Fallo de la Cámara Nacional Civil de Apelaciones, Sala C, I 2 de agosto de I 985 , Del V., J. L., La Ley i985-E, 47.

Fallo de la Cámara Nacional Civil, Sala A, I de mayo de 20r4, E. de R., N., La Ley i 8/08/2004, Iо. 
Fallo de la Cámara Apelaciones Civil y Comercial de Junín, 22 de septiembre de 2009, S., L. F., en DfyP, enero 2010, 2 I 4.

Fallo de la Cámara Nacional Civil, Sala G, 2 de septiembre de 20ı,, C., L. y otros s/ insania, El Dial.com, año xıII, n. ${ }^{\circ} 3$ г 38 .

Fallo de la Cámara Civil y Comercial de Mar del Plata, Sala $3 \cdot{ }^{\text {a }}, 24$ de febrero de 20 I I, L., A. D., Lexis n. ${ }^{\circ} 70068$ I 78.

Fallo de la Suprema Corte de Justica de México, Amparo en revisión I 59/20 I 3 , RACR, I6 de octubre de 2013.

Fallo del Juzgado Nacional en lo Civil n. ${ }^{\circ} 7$, C., M. s/I artículo I 52 ter código civil, exp. 99.247/1996, I8/06/201 2.

Fallo del Juzgado Nacional en lo Civil n. ${ }^{\circ}$ 88, M., D. N. s/ inhabilitación, exp. 91.850/2006, I0/04/2014.

Fallo de Primera Instancia en lo Civil, Comercial y Laboral de la Secretaría n. ${ }^{\circ}$ I de Corrientes, S. O. s/ insania, n. ${ }^{\circ} 202 / 15$, I 8/o8/20 5 .

Fallo de la Cámara Nacional Civil, Sala H, C. A. R. s/ determinación de la capacidad, 22/r 2/2016 (exp. n. ${ }^{\circ}$ 42827-20I3), elDial.com, AA9DCo. 